\title{
Интердискурсивность и особенности ее проявления в спортивном дискурсе
}

\author{
Пантеева К.В. \\ Саратовский государственный технический университет имени Ю. А. Гагарина, \\ Россия, 410054, г. Саратов, ул. Политехническая, 77 \\ E-mail: kse-panteeva@yandex.ru
}

\begin{abstract}
Аннотация. Материалом исследования послужили скрипты видеозаписей международных спортивных соревнований с комментариями российских и британских тележурналистов, а также новостные тексты на сайте Федерации фигурного катания России и на сайте Международного союза конькобежцев. Разграничены понятия «дискурсность», «интердискурсивность» и «интертекстуальность». Выделены и проанализированы признаки интердискурсивности в таких жанрах спортивного дискурса, как спортивный комментарий, спортивная новость и спортивное превью. Сделан вывод о том, что для спортивного дискурса наиболее значимыми являются пересечения с масс-медийным, персональным, политическим и рекламным типами дискурса.
\end{abstract}

Ключевые слова: дискурсивность, спортивный медиа-дискурс, жанры спортивного дискурса.

Для цитирования: Пантеева К.В. 2020. Интердискурсивность и особенности ее проявления в спортивном дискурсе. Вопросы журналистики, педагогики, языкознания, 39 (2): 289-298. DOI $10.18413 / 2712-7451-2020-39-2-289-298$

\section{Interdiscursivity and its peculiarities in sports discourse}

\author{
Ksenia V. Panteeva \\ Yuri Gagarin State Technical University of Saratov, \\ 77 Politechnicheskaya St, Saratov, 410054, Russian \\ E-mail: kse-panteeva@yandex.ru
}

\begin{abstract}
In many papers dedicated to the problem of crossing discourses, the notion of interdiscursivity is often neglected. Nevertheless, the results of the research showed the significance of interdiscursivity in studying discourse matters. The research is based on video scripts of international figure skating competitions broadcast on Russian and British channels as well as texts posted on Figure Skating Federation of Russia website and International Skating Union website. The research helped differentiate the notions of «discursivity», «interdiscursivity» and «intertextuality» since these terms are often confused and used interchangeably. Discursivity is regarded as the quality of a discourse that characterizes it as an open system. Besides, this characteristic can be the source of interdiscursivity. Whereas interdiscursivity is a phenomenon of overlapping different discourses, intertextuality is the interrelation between texts that can be just one of possible indicators of interdiscursivity. Secondly, particular features of interdiscursivity were singled out and analyzed in such genres of sports discourse as sports commentary, sports news and sports preview. The analysis revealed that sports discourse can overlap with media, personal, political, advertising and many other types of discourse.
\end{abstract}

Keywords: discursivity, sports media discourse, genres of sports discourse.

For citation: Panteeva K.V. 2020. Interdiscursivity and its peculiarities in sports discourse. Issues in Journalism, Education, Linguistics, 39 (2): 289-298 (in Russian). DOI 10.18413/2712-7451-2020-39-2289-298 


\section{Введение}

Язык традиционно понимается как многоуровневая система, как система систем фонологии, морфологии, синтаксиса. Первая половина XX века в лингвистике прошла под знаменем структурализма, а потом генеративной грамматики. Это привело к тому, что уровневая модель, во многом логичная и обусловленная необходимостью изучения структурных единиц языка, была возведена в абсолют: языковые уровни воспринимались как самодостаточные, практически автономные области. Ответом на подобный механистический подход к языку стало формирование новой лингвистической парадигмы - дискурса или, как отмечает Е.С. Кубрякова [2000], когнитивно-дискурсивной парадигмы.

Анализ особенностей разных типов дискурса, действительно, постепенно вышел на первый план, так как то, что именно и каким образом говорит или пишет человек, представляет собой неисчерпаемый источник языкового материала. Учитывая разнообразие экстралингвистических факторов, влияющих на речевую коммуникацию, сложно представить момент, когда дискурсивные исследования утратят свою актуальность. Данная работа посвящена проблеме интердискурсивности - относительно новому понятию в дискурс-анализе.

Как уже отмечено в ряде исследований, интердискурсивность - свойство практически любого типа дискурса, что связано с природой дискурса как такового. Особенно ярко интердискурсивность находит свое проявление в институциональных дискурсах, возможно, в силу их многофункциональности. Спортивный дискурс как один из видов институционального дискурса также характеризуется высокой степенью интердискурсивности, причем в разных жанрах это свойство проявляется по-разному.

Цель данного исследования - проанализировать явление интердискурсивности в спортивном дискурсе. Для решения данной цели был поставлен ряд конкретных задач: 1) проанализировать особенности явления интердискурсивности и ее связи со смежными понятиями «интертекстуальность» и «дискурсность»; 2) сопоставить разные примеры проявления интердискурсивности в таких жанрах спортивного дискурса, как спортивный комментарий, спортивная новость и спортивное превью.

Материал для исследования представлен выборкой из опубликованных источников и лично собранных автором статьи записей устных текстов, посвященных фигурному катанию. Так, жанр спортивного комментария представлен скриптами прямых трансляций международных соревнований по фигурному катанию, жанр спортивного превью и спортивной новости - новостными текстами на сайте Федерации фигурного катания России (https://fsrussia.ru/) и на сайте Международного союза конькобежцев (https://isu.org/).

Не существует единого подхода к понятию «дискурс». Так, Е.Г. Малышева описывает дискурс как «процесс тематически обусловленного общения, детерминированного социально-историческими условиями, специфика которого отражается в совокупности текстов $<\ldots>$ характеризуемых концептуальным, речежанровым и прагмастилистическим своеобразием» [Малышева, 2011, с. 34]. Н.Д. Арутюнова [1990], как нам кажется, дает одно из наиболее полных определений дискурса, описывая его как некий последовательно изложенный, логически стройный текст в комплексе с различными факторами, как языковыми, так и внеязыковыми, а именно прагматическими, экстралингвистическими, социокультурными, психологическими и другими. По ее мнению, дискурс - это текст, насыщенный событиями и фактами, некая речемыслительная деятельность, имеющая четко поставленную цель и непосредственно участвующая во взаимной связи людей с происходящими внутри их сознания когнитивными процессами.

Большинство исследователей, например, В.И. Карасик [2002], Б.А. Зильберт и А.Б. Зильберт [2001], относят спортивный дискурс к институциональному статусноориентированному дискурсу, то есть типу дискурса, обслуживающему определенный социальный институт (в нашем случае сферу спорта) и характеризующемуся относительной фиксированностью коммуникативных ролей, клишированностью, нацеленностью на 
структуру, меньшей обусловленностью контекстом [Макаров, 2003]. Л. С. Бейлинсон [2009] подчеркивает значимость институционального дискурса, выделяя следующие его функции: 1) перформативную - вычленение действий, определяющих суть социального института; 2) нормативную - установление правил поведения между институтом и обществом; 3) презентационную - создание образа института и его агентов; 4) парольную установление границы между агентами и клиентами института.

К.В. Снятков [2008] подчеркивает, что главная характеристика спортивного дискурса - трансляция смыслов, определяющих спортивную деятельность. Значимость спортивной тематики как конституирующего элемента подчеркивает и Е.Г. Малышева [2011]. Тем не менее, если мы допускаем, что к спортивному дискурсу относятся любые тексты спортивной или околоспортивной тематики, возникает закономерный вопрос: относится ли к спортивному дискурсу беседа о результатах финала Гран-при за чашкой чая? Можем ли мы считать учебники, посвященные спорту, и нормативно-правовые документы, регламентирующие проведение соревнований, примерами спортивного дискурса, а не педагогического и делового дискурсов соответственно? Можно привести немало подобных примеров, когда спортивный дискурс в значительной мере пересекается с научным, политическим, рекламным и массмедийным дискурсом.

Н.Н. Кислицына и Е.А. Новикова [2017] объясняют подобную особенность спортивного дискурса тем фактом, что спортивные события высокого уровня часто связаны с бизнесом и экономикой, рекламой, политикой. Помимо этого, спорт, с одной стороны, отражает условия существования участников института спорта, с другой стороны, оказывает влияние на формирование ценностных ориентиров. Повышенная эмоциональность и экспрессивность спортивного дискурса не только обеспечивают воспитательную и рекреационную функции, но и помогают получить эмоциональную разрядку [Зубчинский, 2015]. Подобная «разносторонность» и многофункциональность спортивного дискурса обусловливают его неизбежные связи с другими типами дискурса. Т.П. Попова [2015] также отмечает, что граница между институциональными дискурсами нередко настолько условна, что определить точную разновидность того или иного институционального дискурса не всегда представляется возможным.

Многие ученые склонны называть явление, когда в одной точке наблюдается пересечение двух и более дискурсов, интердискурсивностью. Несмотря на то, что интердискурсивность - новое явление в лингвистике, определение данного термина вызывает немало дискуссий. Так, У.А. Жаркова [2014] описывает интердискурсивность как интеграцию различных коммуникативно-прагматических черт в рамках одного дискурса. Г.В. Прокофьев [2013] определяет интердискурсивность как взаимодействие дискурсов различного семантического уровня в контексте поликодового текста. В ряде работ [Олизько, 2009; Шевченко, 2011] интердискурс анализируется как некое лингвосоциокультурное явление. В других работах [Белоглазова, 2009; Jianguo, 2011; Bullo, 2017], напротив, подчеркивается когнитивный характер интердискурсивности. Согласно данному подходу, интердискурсивность - свойство процесса мышления, находящее отражение в интертекстуальных включениях. В.Е. Чернявская [2013] также отмечает связь интердискурсивности и мышления, рассматривая явление интердискурсивности как определенные когнитивные процессы, предваряющие их конкретную реализацию в тексте.

А.Б. Зильберт [2001], описывая точки пересечения спортивного дискурса с другими дискурсами, оперирует термином «интертекстуальность», хотя, как мы рассмотрели выше, данное явление является примером скорее интердискурсивности, а не интертекстуальности. Данные категории действительно взаимосвязаны, но не могут быть отождествлены, поскольку интертекстуальность - это «многомерная связь отдельного текста с другими текстами - по линиям содержания, жанрово-стилистических особенностей, структуры, формально-знакового выражения» [Гордиевский, 2006, с. 8]. Таким образом, интертекстуальность может указывать на наличие интердискурсивности, так как взаимосвязь между раз- 
личными текстами может служить отражением связи между дискурсами [Allen, 2000; Koskela, 2013; Иерусалимская, 2016]. Тем не менее, отсутствие признаков интертекстуальности никоим образом не сигнализирует об отсутствии интердискурсивности, поскольку интердискурсивность - более глобальное понятие по отношению к интертекстуальности.

Н.Ю. Георгинова [2014] объясняет феномен интердискурсивности комплексным и взаимосвязанным характером познавательной деятельности человека, вербализирующейся в различных типах дискурса. С.А. Данилова [2015] рассматривает интердискурсивость как следствие дискурсной гетерогенности - явления, когда тексты, принадлежащие сфере какого-либо дискурса, строятся по законам другого дискурса. Более того, исследователь выделяет два типа дискурсной гетерогенности: облигаторную (при которой сам тип дискурса предполагает селективные включения из другого типа дискурса) и интенциональную (когда автор текста специально использует языковые средства другого типа дискурса, как правило, для большей экспрессивности). В.Е. Чернявская [2007], говоря об интердискурсивности, отмечает открытость дискурса, то есть дискурс в принципе не может рассматриваться как изолированная единица, поскольку строится из различных типов текста и входит в дискурсное метапространство. Подобную открытость текста В.Е. Чернявская называет «дискурсивность», и именно в ней она видит основную причину явления интердискурсивность.

\section{Результаты и их обсуждение}

Е.Г. Малышева отразила вышеобозначенные свойства дискурса в дефиниции спортивного дискурса, характеризуя его как «сложное дискурсивное образование, дискурсивное пространство, в которое входят дискурсивные разновидности, выделяемые по разным основаниям и критериям $<\ldots>$, но характеризующиеся прежде всего тематической и концептуальной общностью» [Малышева, 2011, с. 16]. Границы спортивного дискурса действительно весьма размыты: выделить спортивный дискурс в чистом виде, скорее всего, невозможно хотя бы из-за того, что современный спортивный дискурс сращен с массмедийным дискурсом.

Как и любой другой дискурс, спортивный дискурс имеет полевую структуру: к его ядру относится собственно спортивный медиадискурс. Спортивный дискурс, реализуемый через СМИ, относится к ядерной зоне спортивного дискурса, поскольку именно в журналистском спортивном дискурсе такие конституирующие элементы дискурса, как субъектно-объектные характеристики общения, соответствующие условия коммуникации, цель коммуникации оказываются дискурсивно маркированными [Солодовникова, 2010]. Именно в спортивном медиадискурсе максимально возможно проявляется институциональный характер спортивного дискурса.

На периферии спортивного дискурса, в свою очередь, находятся коммуникативные ситуации, тематически связанные со спортом, однако их дискурсивно-когнитивная доминанта лишь косвенно связана со спортивными явлениями. Так, например, обсуждение спортивных соревнований в ситуации повседневного общения относится скорее к персональному типу дискурса; официальное объявление состава жюри перед началом соревнований - принадлежит преимущественно сфере делового дискурса, судебное разбирательство по вопросу дисквалификации какого-либо спортсмена - юридическому. Ряд подобных примеров можно продолжать практически бесконечно, находя области пересечения периферийных зон различных дискурсов.

Стоит отдельно отметить, что интердискурсивность проявляется не только на периферии дискурсов: жанры, которые относятся к ядру какого-либо дискурса, могут также нести в себе элементы других дискурсов. Рассмотрим данное явление на примере некоторых жанров спортивного дискурса.

Большинство исследователей (К.В. Снятков, Е.Г. Малышева, О.А. Панкратова, Е.С. Солнцева), сходятся во мнении, что ядерным жанром спортивного дискурса является 
спортивный комментарий. Спортивный комментарий представляет собой жанр спортивного дискурса, в рамках которого осуществляется коммуникативный процесс, происходящий между спортивным комментатором и телезрителями трансляции спортивного соревнования [Lewandowski, 2012]. В зависимости от числа комментаторов, реципиентом могут выступать не только телезрители, но и другие комментаторы. Среди жанрообразующих характеристик спортивного комментария стоит отметить наличие одной или нескольких макротем, обусловливающих как заранее подготовленный, так и спонтанный блок спортивного комментария [Augendreetal., 2018].

Интересен тот факт, что заранее подготовленная часть комментария (информация о спортсмене, тренере, регламенте соревнования, текущих рекордах), как правило, не выходит за границы собственно спортивного дискурса. Та же часть спортивного комментария, которая продуцируется непосредственно во время выступления, характеризуется определенной степенью интердискурсивности. В первую очередь, мы можем наблюдать значительные включения персонального (разговорного) дискурса. Наиболее ярко данная особенность проявляется в тех случаях, когда в роли спортивного комментатора выступает непрофессиональный журналист, например, тренер или спортсмен. В таких случаях возможен не только переход на разговорно-обиходный стиль речи, но и значительные отступления от макротемы, т. е. рассуждения, опосредованно связанные с происходящим на стадионе, а иногда и вовсе не связанные с комментируемым соревнованием. Так, во время короткой программы женщин на этапе гран-при по фигурному катанию 2018 года во Франции (прямую трансляцию комментировали И.И. Авербух и Т.А. Тарасова) прозвучал следующий диалог:

«-<..> Звонило сто человек, и все спрашивают "Как?", и я сразу вешаю трубку.

- Татьяна Анатольевна очень эмочиональный человек...

- Tы знаешь, я вполне довольна тем, что я эмочиональный человек... Вряд ли я была бы довольна, если бы я была деревяшкой».

Данному диалогу предшествовало обсуждение того, насколько успешно выступили российские фигуристки и смогут ли они составить конкуренцию японским спортсменкам. В определенный момент Т.А. Тарасова, желая, видимо, подчеркнуть как собственные переживания, так и общий накал страстей вокруг всей ситуации, отмечает, что ей многие звонят и интересуются ее мнением, но она сразу же вешает трубку. Если эта часть комментария кажется связанной с темой комментируемого события, то последующие реплики об эмоциональности Т.А. Тарасовой, о том, хорошо это или плохо имеют весьма косвенное отношение к спорту. Более того, в этой части комментария присутствуют лексические маркеры персонального дискурса (ты знаешь, деревяшка).

Спортивные комментарии международных соревнований нередко имеют политическую подоплеку. Таким образом, можно наблюдать пересечение спортивного и политического дискурсов. Многие исследователи отмечают, что момент агональности всегда сближает спортивный и политический дискурсы. Конечно, неправильно было бы говорить о тотальной политизированности спорта, но когда речь идет о борьбе представителей разных стран за победу на этапах гран-при, чемпионатах мира или Олимпийских играх, политическая составляющая в большинстве случаев неизбежна. Рассмотрим следующий пример:

«Но нас волнует, как наши девочки... лучше о своих, да, заботиться? Как наши девочки прокатаются...»

Данный комментарий также прозвучал на этапе гран-при по фигурному катанию 2018 года во Франции: комментатор открыто говорит о том, что для нее главное - выступление российских спортсменок, а не представителей других стран. Связь политического и спортивного дискурсов здесь, конечно, опосредована: доминантой политического дискурса является борьба за власть [Шейгал, 2000], которая, на первый взгляд, в анализируемом комментарии не наблюдается. Тем не менее, в данном случае стоит расширить понятие «борьбы за власть» до «борьбы за доминирование». Тогда станет возможным отметить не 
просто субъективизм комментатора из-за личных преференций, но и общую установку на ведущую роль российских спортсменов, что несколько противоречит априорным требованиям к журналисткой объективности, хотя и воспринимается большинством телезрителей как логичное проявление патриотизма.

Пересечение спортивного дискурса с массмедийным наблюдается не только в жанре спортивного комментария, но и во всех основных жанрах спортивного дискурса (спортивная новость, спортивная аналитическая статья, спортивное интервью, спортивная пресс-конференция и др.), поскольку, как упоминалось выше, эти два вида дискурса неотделимы друг от друга. Именно поэтому, все чаще в научной литературе встречается термин «спортивный медиадискурс», отражающий высокую степень сращенности двух дискурсов. Так, спортивный и массмедийный дискурс объединяет функция воздействия текста на реципиента, стремление сформировать особое видение происходящего, ориентация на рекреационные функции. Рассмотрим следующий пример:

Canadian ice dancers Kaitlyn Weaver/Andrew Poje are looking back at a distinguished career with three World medals and multiple other medals and titles and they are still major players in the game as they proved by taking the silver medal at the recent ISU Four Continents Figure Skating Championships 2019. [За плечами канадских танцоров на льду Кэтлин Уивер и Андре Поже вылающаяся карьера: в их арсенале три медали чемпионатов мира и множество других наград и титулов. Они по-прежнему в игре: они это доказали, выиграв серебряную медаль на недавнем чемпионате четырех континентов 2019 года.]

В данном примере мы видим отрывок спортивной новости о победе канадских фигуристов на чемпионате четырех континентов, однако автор не просто сообщает читателям о победе: в новости также упоминаются многочисленные медали данного дуэта, полученные на крупных соревнованиях, причем автор логически связывает предыдущие и настоящие успехи канадцев. Помимо фактуальной информации можно наблюдать и оценочные компоненты (arelookingbackatadistinguishedcareer; majorplayersinthegame), нацеленные на формирование у читателей положительного образа спортсменов, что является характерной чертой массмедийного дискурса.

В некоторых работах спортивный дискурс даже рассматривается как разновидность массмедийного дискурса наравне с политическим, экономическим и др. типами дискурса, реализуемыми через СМИ. Подобный подход нам кажется не совсем правомерным, поскольку в этом случае происходит смешение принципиально разных классификаций дискурса: деление на спортивный, политический, юридический и пр. дискурсы строится прежде всего на сфере функционирования того или иного дискурса, тогда как в основе выделения массмедийного дискурса лежит канал связи, посредством которого реализуется дискурс.

Отдельно хотелось бы отметить пересечение спортивного и рекламного дискурсов в жанре спортивного превью - специфическом жанре спортивного дискурса, целью которого является информирование читателей о предстоящем спортивном соревновании (что роднит его с жанром спортивного анонса). Здесь же дается предварительная оценка шансов участников соревнования на победу или призовые места (что в некотором роде роднит его с жанром аналитической статьи). Рассмотрим следующий пример:

The Pairs event is highlighted by the ongoing duel between four-time World Champions Aliona Savchenko/ Robin Szolkowy (GER) and reigning World and European Champions Tatiana Volosozhar/ Maxim Trankov (RUS). Volosozhar/Trankov (seasons best 237.71 points) started strongly into the season, but the Germans (seasons best 227.03 points) handed them their first defeat in 20 months at the ISU Grand Prix of Figure Skating Final in December. [Соревнования спортивных пар особенно интересны продолжающейся дуэлью между четырехкратными чемпионами мира Аленой Савченко / Робином Шолковы (Германия) $и$ действующими чемпионами Европь и мира Татьяной Волосожар / Максимом Траньковым (Россия). Пара Волосожар / Траньков (лучший результат в сезоне - 237.71 балл) хорошо начали сезон, но именно немецкий дуэт (лучший результат в сезоне - 
227.03 балла) нанесли им первое за 20 месячев поражение на финале Гран-при в декабpe.] (Превью чемпионата Европы 2014 года).

Как мы видим, в данном спортивном превью представлено довольно много фактуальной информации (регалии, лучшие результаты в сезоне и пр.), однако подача этой информации совсем иная: в тексте совершенно точно считывается оценочная информация, которая формируется за счет сложного взаимодействия языковых единиц текста. Так, метафоры военной тематики (theongoingduel, <..> arechasing the Canadians), вкрапляясь между громкими титулами, придают им оценочный оттенок. Подробное перечисление прежних побед спортсменов также направлено на привлечение внимания к соревнованию. Таким образом, в спортивном превью оценка заявленных спортсменов несет не столько информативный характер, сколько нацелена на привлечение потенциальных зрителей или телезрителей. Причем привлечение массовой аудитории означает как медийный, так и коммерческий успех [Augendreetal., 2018]. Поэтому в спортивном превью максимально красочно описываются причины, почему ожидаемое мероприятие нужно обязательно посмотреть или посетить: внимание аудитории могут привлечь титулованные участники, обещание напряженной борьбы и многое другое. Как мы видим, подобные цели во многом преследует и рекламный дискурс: коммерческая составляющая также сохраняется.

\section{Заключение}

Итак, интердискурсивность - явление взаимопроникновения и взаимодействия дискурсов, которое может проявляться через интертекстуальность, т. е. как вкрапление одного текста в другой. Однако отсутствие признаков интертекстуальности не означает обязательного отсутствия интердискурсивности: интердискурсивность обусловлена особыми когнитивными процессами, предваряющими сочетание элементов разных дискурсов в языке. Одной из возможных причин интердискурсивности является такое свойство дискурса, как дискурсивность, подразумевающая принципиальную открытость дискурса и вхождение каждого типа дискурса в единое дискурсное метапространство. Спортивный дискурс также характеризуется высокой степенью интердискурсивности как в периферийной (связь с научным, юридическим, педагогическим, деловым и др. дискурсами), так и в ядерной зоне. В связи со сращением спортивного дискурса с массмедийным все основные жанры спортивного дискурса имеют характеристики, присущие журналистскому дискурсу.

Проанализированный материал также показал, что в спортивном комментарии мы можем наблюдать элементы персонального дискурса, особенно при привлечении непрофессиональных комментаторов. Пересечение с политическим дискурсом возможно при комментировании крупных международных соревнований. Специфика жанра спортивного превью, в свою очередь, подразумевает пересечение спортивного и рекламного дискурсов.

Несомненно, проблема интердискурсивности и единого дискурсивного пространства требует дальнейшего анализа. Так, за рамками нашего исследования остались механизмы взаимопроникновения дискурсов на когнитивном и лингвопрагматическом уровне.

\section{Список литературы}

1. Арутюнова Н.Д. 1990. Дискурс. В кн.: Лингвистический энциклопедический словарь. Гл. ред. В.Н. Ярцева. М., Советская энциклопедия: 168 с.

2. Бейлинсон Л.С. 2009. Профессиональный дискурс как предмет лингвистического изучения. Вестник Волгоградского государственного университета. Языкознание, 1 (9): 145-149.

3. Белоглазова Е.В. 2009. Полидискурсивность как особый исследовательский фокус. Известия Санкт-Петербургского университета экономики и финансов, 3: 66-71.

4. Георгинова Н.Ю. 2014. Интердискурсивность, интертекстуальность, полифония: к соотношению понятий. Вестик Ленингр. гос. ун-та им. А.С. Пушкина, 1(1): 149-155.

5. Гордиевский А.А. 2006. Категория интердискурсивности в научно-дидактическом тексте (на материале лекций на русском и немецком языке). Автореф. дис. ... канд. филол. наук. Тюмень, 24 с. 
6. Данилова С.А. 2015. Институциональный дискурс, интердискурсивность и дискурсная гетерогенность. Концепт - «Concept», Т. 30: 316-320. URL: http://e-koncept.ru/2015/65134.htm. (дата обращения: 23 января 2020).

7. Жаркова У.А. 2014. К проблеме интердискурсивности типа текста «спортивный анонс» (на материале немецкоязычных текстов). Вестник Нижневартовского государственного университета, 14: 21-29.

8. Зильберт А.Б. 2001. Спортивный дискурс: точки пересечения с другими дискурсами (проблемы интертекстуальности). В кн.: Язык, сознание, коммуникация. Сб. статей. Отв. ред. В.В. Красных, А. И. Изотов. М., МАКС Пресс, вып. 19: 103-112.

9. Зильберт Б.А., Зильберт А.Б. 2001. Спортивный дискурс: базовые понятия и категории; исследовательские задачи. В кн.: Язык, сознание, коммуникация. Сб. статей. Отв. ред. В.В. Красных, А.И. Изотов. М., МАКС Пресс, вып. 17: 45-55.

10. Зубчинский И.В. 2015. Спортивный дискурс и средства массовой информации. Евразийский вестник гуманитарных исследований, 1 (2): 44-45.

11. Иерусалимская А.О. 2016. Интертекстуальность vs интердискурсивность как сложившийся дискурс. Вестник Северного (Арктического) федерального университета. Серия: Гуманитарные и социальные науки, 2: 104-111.

12. Карасик В.И. 2002. Языковой круг: личность, концепты, дискурс. Волгоград, Перемена, 477 с.

13. Кислицына Н.Н., Новикова Е.А. 2017. Спортивный дискурс в системе институциональных видов дискурса. Актуальные проблемы филологии и педагогической лингвистики, 2 (26): 28-35.

14. Кубрякова Е.С. 2000. О понятии дискурса и дискурсивного анализа в современной лингвистике. В кн.: Дискурс, речь, речевая деятельность: функциональные и структурные аспекты. Серия: Теория и история языкознания. Отв. ред. Ромашко С.А. и др. М., Институт научной информации по общественным наукам РАН: 7-21.

15. Макаров М.Л. 2003. Основы теории дискурса. М., ИТДГК «Гнозис», 280 с.

16. Малышева Е.Г. 2011. Русский спортивный дискурс: лингвокогнитивное исследование. Омск, Издательство ОмГУ, 324 с.

17. Олизько Н.С. 2009. Семиотико-синергетическая интерпретация особенностей реализации категорий интертекстуальности и интердискурсивности в постмодернистском художественном дискурсе. Автореф. дис. ... д-ра филол. наук. Челябинск, 43 с.

18. 1Попова Т.П. 2015. Характеристики институционального дискурса. Историческая и социально-образовательная мысль, т. 7, 6 (2): 295-300.

19. Прокофьев Г.В. 2013. Категория интердискурсивности как средство организации медиадискурса. Вестник Томского государственного педагогического университета, 5 (133): 77-79.

20. Снятков К.В. 2008. Коммуникативно-прагматические характеристики телевизионного спортивного дискурса. Автореф. дис. .... канд. филол. наук. Вологда, 19 с.

21. Солодовникова А.Н. 2010. Основные способы воздействия в социальной рекламе. Известия Саратовского университета. Новая серия. Серия: Филология. Журналистика, т. 10 (1): $13-17$.

22. Чернявская В.Е. 2007. Открытый текст и открытый дискурс: интертекстуальность дискурсивность - интердискурсивность. Стил, Белград, 6: 11-26.

23. Чернявская В.Е. 2013. Текст в медиальном пространстве. М., Книжный дом «Либроком», 232 с.

24. Шевченко В.Д. 2011. Интерференция дискурсов в англоязычной публицистике. Автореф. дис. ... канд. филол. наук. Санкт-Петербург, 40 с.

25. Шейгал Е. И. 2000. Семиотика политического дискурса. Дис. ... д-ра филол. наук. Волгоград, $440 \mathrm{c}$.

26. 2Allen G. 2000. Intertextuality, London, Routledge, 252 p.

27. Augendre S., Kupść A., Boyé G., Mathon C. 2018. Live TV sports commentaries: specific syntactic structures and general constraints. In: The Grammar of Genres and Styles: From Discrete to Non-Discrete Units: 194-218.

28. Bullo S. 2017. Investigating intertextuality and interdiscursivity in evaluation: the case of conceptual blending. Language and Cognition, 9 (4): 709-727. 
29. Jianguo W. 2011. Understanding interdiscursivity: a pragmatic model. Journal of Cambridge Studies, 6: 95-115. Available at: http://www.journal.acs-cam.org.uk/data/archive /2011/201123article8.pdf (accessed 23.01.2020).

30. Koskela M. 2013. Same, same, but different: Intertextual and interdiscursive features of communication strategy texts. Discourse \& Communication, 7 (4): 389-407.

31. Lewandowski M. 2012. The language of online sports commentary in a comparative perspective. Lingua Posnaniensis, 54 (1): 65-76. Available at: https://doi.org/10.2478/v10122-012-00060 (accessed 22.01.2020).

\section{References}

1. Arutyunova N.D. 1990. Diskurs [Discourse]. In.: Lingvisticheskii entsiklopedicheskii slovar' [Linguistic Encyclopedic Dictionary]. Ed: V.N. Jarceva. M., Publ., Sovetskaya entsiklopediya: 168 p.

2. Beylinson L.S. 2009. Professional discourse as the subject of linguistic investigation. Science Journal of Volgograd State University. Linguistics, 1 (9): 145-149 (in Russian).

3. Beloglazova E.V. 2009. Polydiscoursity as special research focus. Izvestiâ SanktPeterburgskogo gosudarstvennogo èkonomičeskogo universiteta, 3: 66-71 (in Russian).

4. Georginova N.Yu. 2014. Interdiskursivnost', intertekstual'nost', polifoniya: k sootnosheniyu ponyatiy [Interdiscursiveness, intertextuality, polyphony: to the correlation of concepts]. Vestik Leningr. gos. un-ta im. A. S. Pushkina - Vestik Leningrad state University of them A.S. Pushkin, 1(1): 149-155.

5. Gordievskiy A.A. 2006. Kategoriya interdiskursivnosti v nauchno-didakticheskom tekste (na material lektsiy na russkom i nemetskom yazyke) [The category of inter-discursiveness in the scientific didactic text (based on lectures in Russian and German)]. Avtoref. dis. ... cand. filol. sciences. Tyumen', 24 p.

6. Danilova S.A. 2015. Institutsional'nyy diskurs, interdiskursivnost' i diskursnaya geterogennost' [Institutional Discourse, Inter-Discursiveness, and Discourse Heterogeneity]. Nauchnometodicheskiy elektronnyy zhurnal «Kontsept» - Scientific and methodological electronic journal "Concept", T. 30: 316-320. URL: http://e-koncept.ru/2015/65134.htm (accessed: 23.01.2020).

7. Zharkova U. A. 2014. To the problem of interdiscursivity of "sports announcement" type of text (based on the german-language texts). Bulletin Of Nizhnevartovsk State University, 14: 21-29.

8. Zil'bert A.B. 2001. Sportivnyi diskurs: tochki peresecheniya s drugimi diskursami (problemy intertekstual'nosti) [Sports discourse: intersection points with other discourses (intertextuality problems)]. In.: Yazyk, soznanie, kommunikatsiya [Language, Consciousness, Communication]. Sb. statei. Eds. Krasnykh V.V., Izotov A I. M., Publ., MAKS Press, vyp.19: 103-112.

9. Zil'bert B.A., Zil'bert A.B. 2001. Sportivnyi diskurs: bazovye ponyatiya i kategorii; issledovatel'skie zadachi [Sports discourse: basic concepts and categories; research tasks]. In.: Yazyk, soznanie, kommunikatsiya [Language, Consciousness, Communication]. Sb. statei. Eds. V.V. Krasnykh, A.I. Izotov. M., Publ., MAKS Press, 17: 45-55.

10. Zubchinskiy I.V. 2015. Sportivnyy diskurs i sredstva massovoy informatsii [Sports Discourse and Mass Media]. Evraziyskiy vestnik gumanitarnykh issledovaniy, 1(2): 44-45.

11. Ierusalimskaya A.O. 2016. Intertextuality vs interdiscursivity as a formed discourse. Vestnik Severnogo (Arkticheskogo) federal'nogo universiteta. Seriya: Gumanitarnye i sotsial'nye nauki, 2: 104111 (in Russian).

12. Karasik V.I. 2002. Yazykovoy krug: lichnost', kontsepty, diskurs [Language circle: personality, concepts, discourse]. Volgograd, Publ., Peremena, 477 p.

13. Kislitsyna N.N., Novikova E.A. 2017. Sports discourse in the system of institutional types of discourse. Current issues in philology and pedagogical linguistics, 2 (26): 28-35 (in Russian).

14. Kubryakova E.S. 2000. O ponyatii diskursa i diskursivnogo analiza v sovremennoy lingvistike [On the concept of discourse and discursive analysis in modern linguistics]. In.: Diskurs, rech', rechevaya deyatel'nost': funktsional'nye i strukturnye aspekty [Discourse, speech, speech activity: functional and structural aspects]. Sb. obzorov. Eds. Romashko S.A. et al. Ser. Teoriya i istoriya yazykoznaniya. M., Publ., Institut nauchnoy informatsii po obshchestvennym naukam RAN: 7-21.

15. Makarov M.L. 2003. Osnovy teorii diskursa [Fundamentals of Discourse Theory]. M., Publ., ITDGK «Gnozis», $280 \mathrm{p}$.

16. Malysheva E.G. 2011. Russkiy sportivnyy diskurs: lingvokognitivnoe issledovanie [Russian sports discourse: linguistic-cognitive research]. Omsk, Publ., Izdatel'stvo OmGU, 324 p. 
17. Oliz'ko N.S. 2009. Semiotiko-sinergeticheskaya interpretatsiya osobennostey realizatsii kategoriy intertekstual'nosti i interdiskursivnosti v postmodernistskom khudozhestvennom diskurse [The semiotic-synergetic interpretation of the implementation features of the categories of intertextuality and inter-discursiveness in postmodern art discourse]. Avtoref. dis. ... d-ra filol. sciences. Chelyabinsk, 43 p.

18. Popova T.P. 2015. Characteristics of Institutional Discourse. Historical and Social Educational ideas, t. 7, 6 (2): 295-300 (in Russian).

19. Prokof'ev G.V. 2013. The Category of Interdiscourse as a Means of Organizing Media Discourse. Tomsk State Pedagogical University Bulletin, 5 (133): 77-79.

20. Snyatkov K.V. 2008. Kommunikativno-pragmaticheskie kharakteristiki televizionnogo sportivnogo diskursa [Communicative and pragmatic characteristics of television sports discourse]. Avtoref. dis. ... cand. filol. sciences. Vologda, $19 \mathrm{p}$.

21. Solodovnikova A.N. 2010. Osnovnye sposoby vozdeystviya v sotsial'noy reklame [The main methods of exposure in social advertising]. Izvestiya Saratovskogo universiteta. Novaya seriya. Seriya: Filologiya. Zhurnalistika, 10(1): 13-17.

22. Chernyavskaya V.E. 2007. Otkrytyy tekst i otkrytyy diskurs: intertekstual'nost' diskursivnost' - interdiskursivnost' [Opened text and opened discourse: intertextuality - discursivity interdiscursivity]. Stil. Belgrad, 6: 11-26.

23. Chernyavskaya V.E. 2013. Tekst v medial'nom prostranstve [Text in the medial space]. M., Publ., Knizhnyy dom «Librokom», 232 p.

24. Shevchenko V.D. 2011. Interferentsiya diskursov v angloyazychnoy publitsistike [Discourse Interference in English Journalism]. Avtoref. dis. ... cand. filol. sciences. Sankt-Peterburg, 40 p.

25. Sheygal E. I. 2000. Semiotika politicheskogo diskursa [Semiotics of Political Discourse]. Dis. ... d-ra filol. sciences. Volgograd, $440 \mathrm{p}$.

26. Allen G. 2000. Intertextuality, London, Routledge, 252 p.

27. Augendre S., Kupść A., Boyé G., Mathon C. 2018. Live TV sports commentaries: specific syntactic structures and general constraints. In: The Grammar of Genres and Styles: From Discrete to Non-Discrete Units: 194-218.

28. Bullo S. 2017. Investigating intertextuality and interdiscursivity in evaluation: the case of conceptual blending. Language and Cognition, 9 (4): 709-727.

29. Jianguo W. 2011. Understanding interdiscursivity: a pragmatic model. Journal of Cambridge Studies, 6: 95-115. Available at: http://www.journal.acs-cam.org.uk/data/archive /2011/201123article8.pdf (accessed 23.01.2020).

30. Koskela M. 2013. Same, same, but different: Intertextual and interdiscursive features of communication strategy texts. Discourse \& Communication, 7 (4): 389-407.

31. Lewandowski M. 2012. The language of online sports commentary in a comparative perspective. Lingua Posnaniensis, 54 (1): 65-76. Available at: https://doi.org/10.2478 /v10122-012-00060 (accessed 22.01.2020).

\section{ИНФОРМАЦИЯ ОБ АВТОРЕ}

Пантеева Ксения Владимировна, старший преподаватель кафедры иностранных языков и профессиональной коммуникации Саратовского государственного технического университета им. Ю.А. Гагарина, г. Саратов, Россия

\section{INFORMATION ABOUT THE AUTHOR}

Ksenia V. Panteeva, senior lecturer at the Department of foreign languages and professional communication, Yuri Gagarin Saratov state technical University, Saratov, Russia 